\title{
EXTRACTION OF METALS BY MELTS OF EASILY FUSIBLE ORGANIC SUBSTANCES IN CHEMICAL ANALYSIS
}

E.V.Zlobina, A.I.Zebreva

The efficiency of application of higher carbonic acids and also of their mixtures with differentiating additives of various nature as a metal extraction agents is shown. The complex of experimental investigations and established theoretical regularities of extraction of metals by melts has enabled the development of new combined methods of determination of metals in natural and technogenic materials. The results of the researches carried out at the department of analytical chemistry of al-Farabi KazNU during 30 years are generalized.

УДК 543.5

\section{МЕСТО И РОЛЬ ЭЛЕКТРОХИМИЧЕСКИХ ПРЕОБРАЗОВАТЕЛЕЙ ЭНЕРГИИ В ЭНЕРГЕТИКЕ}

\author{
АП.Курбатов \\ Казахский национальный университет имени аль-Фараби, г.Алматы \\ Kurbatovap@gmail.com
}

\begin{abstract}
Рассмотрено положение электрохимического способа преобразования энергии химической реакции в общем процессе производства энергии. Показаны эффективные пути и тенденции его реализации. Рассмотрены варианты электрохимических систем для получения, накопления и хранения энергии.
\end{abstract}

Общепризнано, что основным фактором, определяющим развитие материальной культуры, является создание и использование источников энергии. Так, в наиболее развитых странах используемая мощность разнообразных источников энергии составляет до 10 киловатт на человека, что в 100 раз больше, чем средняя мускульная мощность одного человека.

Роль энергии в народном хозяйстве хорошо иллюстрируется рисунком 1 (данные относятся еще к 1968 г. и составлены по материалам ООН и Международного банка реконструкции и развития.). По горизонтальной оси отложен валовой национальный продукт (ВНП) для различных стран (в долларах на человека), а по вертикали - потребление энергии в пересчете на каменный уголь (в килограммах на человека).

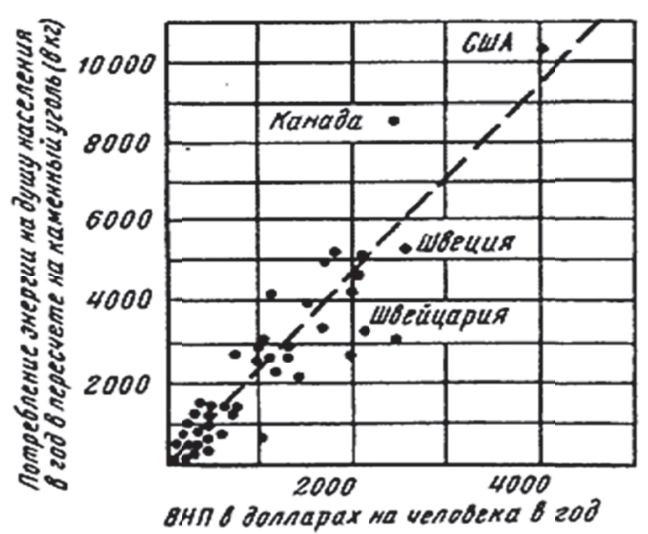

Рисунок 1 - Связь энерговооруженности и ВНП

В пределах естественной флуктуации видно, что существует прямая пропорциональность. Сейчас в качестве основных энергетических ресурсов используются торф, уголь, нефть, природный газ. Запасенная в них химическая энергия была накоплена на протяжении тысячелетий благодаря биологическим процессам. В ближайшее столетие они 
будут исчерпаны. Основным способом извлечения этой энергии является химическое окисление (горение).

Основу современной энергетики составляют теплосиловые установки паротурбинных электростанций, которые обеспечивают превращение энергии химической реакции окисления в электрическую. Остальные энергоисточники лишь дополняют это производство.

Так, например, потребность России в электроэнергии удовлетворяют электростанции, свыше 20\% которых составляют ГЭС, более 10\% - АЭС и почти $70 \%$ - тепловые электростанции (ТЭС).

Вклад нетрадиционных источников энергии не превышает $3 \%$.

Одна из основных тенденций развития тепловых электростанций - увеличение мощности единичных агрегатов, что позволяет осуществлять процесс более эффективно, и быстрыми темпами наращивать энерговооружённость.

Однако, в среднем, не более $30 \%$ энергии сгорания топлива преобразуется в электроэнергию, а из выработанной с такими большими затратами топлива электроэнергии, ещё до $25 \%$ теряется при доставке энергии потребителям.

В качестве первоочередных задач энергетики вытекает необходимость поиска путей повышения коэффициента преобразования энергии окисления в электрическую и развития автономных видов источников энергии. К этому следует добавить еще и самые высокие показатели загрязнения воздуха от теплостанций (Рисунок 2).

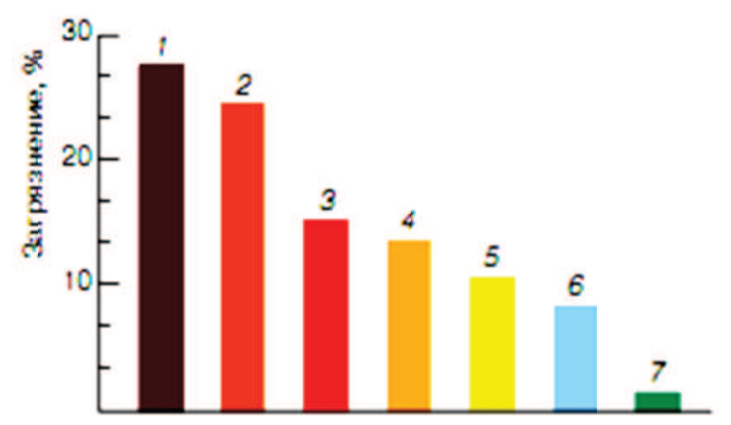

1 - теплоэнергия, 2 - черная металлургия, 3 - нефтедобыча и нефтепереработка, 4 - автотранспорт, 5 цветная металлургия, 6 - промышленность стройматериалов, 7 - химическая промышленность

Рисунок 2 - Показатели загрязнения атмосферы различными отраслями техники в России.

Самым высоким КПД трансформации энергии окисления в электрическую характеризуется электрохимические преобразование, реализуемое в химических источниках тока (ХИТ). Электрохимические преобразователи позволяют также осуществлять автономное использование источников энергии. Однако, для энергетики больших мощностей приходится отказываться от ряда весьма эффективных процессов трансформирования энергии. Так, например, в топливных газовых элементах, где происходит прямое превращение химической энергии окисления водорода в электроэнергию, этот процесс уже сейчас может осуществляться с высоким КПД, который достигает 70\%. Но возможность применения газовых элементов для энергетики больших мощностей ограничивается весьма малой скоростью диффузионных процессов в электролитах; поэтому на практике плотность потока энергии очень мала, и с квадратного метра электрода можно снимать менее киловатта.

То же самое можно сказать и о солнечных элементах, где снимаемая с одного квадратного метра мощность в среднем не превышает 100 Вт. Практическое прямое использование солнечной энергии в больших масштабах нереально и подходит лишь для автономного варианта. С развитием микроэлектроники появилась и еще одна тенденция в автономном энергообеспечении - это персональное мобильное энерговооружение для носимых приборов (ноутбук, сотовый телефон, фото-, аудио-, видеотехника, навигаторы и т.д.). 
Соответственно, для этих целей, как и для целей энергообеспечения космических, авиа-, подводных и военных объектов предъявляются жесткие требования к эффективности и удельной энергии - энергии в единице массы источника или его объема. В таблице 1 сведены основные характеристики используемых видов энергии с этой точки зрения.

Таблица 1 - Основные характеристики видов энергии

\begin{tabular}{|c|c|c|}
\hline Форма энергии & Вид энергии & $\begin{array}{r}\text { Плотность } \\
\text { энергии }\left[\mathrm{BT} \cdot \mathrm{c} / \mathrm{m}^{3}\right]\end{array}$ \\
\hline Гравитационная & Потенциальная энергия $\omega=\rho \mathrm{gh}$ & $10^{3}$ \\
\hline Механическая & Кинетическая энергия $\omega=\rho / 2 v 2$ & $10^{4}$ \\
\hline Электрическая & Энергия электрического поля $\omega=0,5 \mathrm{DE}$ & $10^{5}$ \\
\hline Магнитная & Энергия магнитного поля $\omega=0,5 \mathrm{BH}$ & $10^{6}$ \\
\hline Тепловая & Энергия фазового перехода $\omega=\rho \Delta \mathrm{h}$ & $10^{7}$ \\
\hline Тепловая & Теплоёмкость $\omega=\rho с р \mathrm{~T}$ & $10^{8}$ \\
\hline Химическая & Гальваническая батарея & $10^{9}-10^{10}$ \\
\hline Химическая & Горение & $10^{10}$ \\
\hline Ядерная & Радиоактивность & $10^{15}$ \\
\hline
\end{tabular}

Как видно из таблицы, кроме ядерной энергии, у химической энергии конкурентов нет. Пока не будет предложено надежного способа автономного питания на ядерном топливе, электрохимические преобразователи будут оставаться для этих целей наиболее перспективными.

Диапазон предполагаемого применения топливных элементов уже сейчас необычайно широк: от мобильных телефонов и ноутбуков до мегаваттных электростанций, работающих исключительно на топливных элементах.

В настоящее время емкость портативного топливного элемента вмещает 120 мл метанола, этого достаточно для обеспечения работы ноутбука мощностью 15 Ватт в течение 10 часов. Что касается стоимости жидкого топлива, то, по оценке специалистов компании, при объемах производства только в США в 35,7 млн. тонн метанола в год и цене 33 цента за галлон можно ожидать, что заправленный картридж будет обходиться покупателю в \$3-5.

С точки зрения стоимости электроэнергии, это не дешевле электроэнергии ТЭС, но для автономного питания это очень выгодно. На рисунке 3 представлена общая схема вариантов трансформирования химической энергии в электрическую.

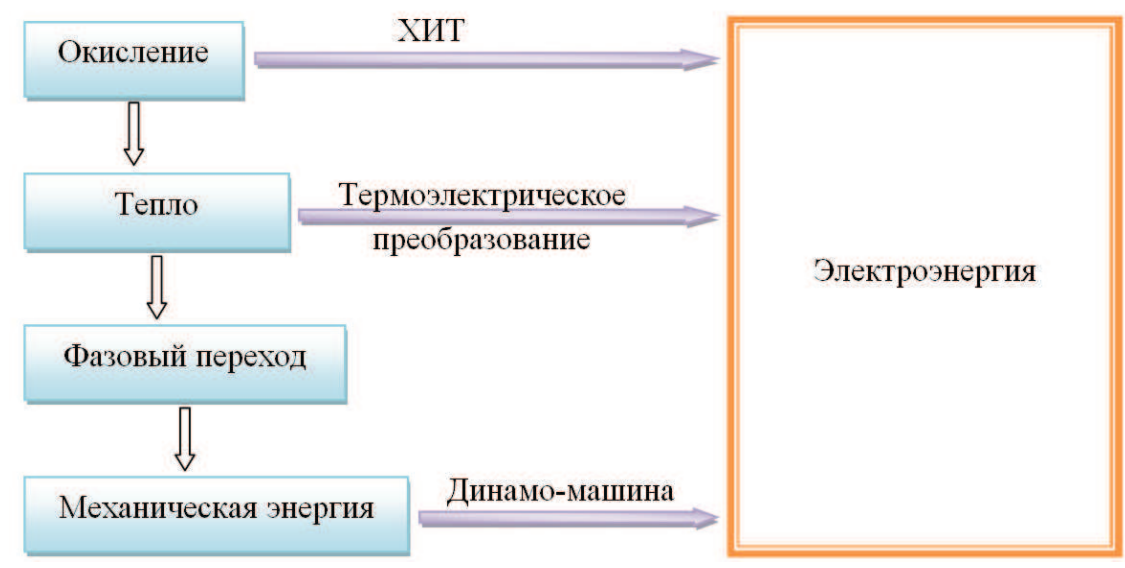

Рисунок 3 - Схема путей преобразования химической энергии в электрическую 
Существуют установки, в которых преобразование теплоты в электроэнергию осуществляется без электромеханических генераторов. $\mathrm{K}$ ним относят магнитогидродинамические генераторы, термоэлектрические генераторы, термоэмиссионные преобразователи энергии.

Для большой энергетики наиболее перспективны установки с магнитогидродинамическим генератором (МГД-генератором). В комплексе с обычной паротурбинной станцией КПД такой комбинированной установки может достигать $50-60 \%$.

Для малых энергетических установок специального назначения находят применение термоэлектрические (ТЭП) и термоэмиссионные (ТЭП) установки прямого преобразования энергии. Действительные значения КПД термоэлементов в лучшем случае достигают нескольких процентов. Этим, а также высокой стоимостью самих термоэлементов, объясняется малая распространённость ТЭГ, несмотря на их крайнюю простоту и отсутствие каких-либо движущихся частей.

Реальный КПД ТЭП тоже не более $7-8 \%$, прежде всего из-за больших потерь теплоты излучения между катодом, имеющим температуру около 2000 К, и анодом - около 1000 К. ТЭГ и ТЭП представляют интерес в сочетании с ядерными источниками теплоты, образуя полностью статичные автономные источники электроэнергии.

Поскольку преобразование энергии химической реакции в электрическую в ХИТ является прямым и лишено множества стадий в отличие от традиционного теплового, оно характеризуется наибольшим КПД.

По принципам работы ХИТ разделяют на три группы: первичные, вторичные и топливные элементы (Рисунок 4). Первичные ХИТ (гальванические элементы) содержат активные вещества на электродах, а после их полного расходования источники прекращают свою работу и требуют замены новыми. Вторичные ХИТ (аккумуляторы) после расходования активных масс (разряда) могут быть приведены в рабочее состояние пропусканием электрического тока через элемент в обратном направлении. Преимущество аккумуляторов перед первичными элементами заключается в том, что их активные вещества могут работать сотни и тысячи циклов.

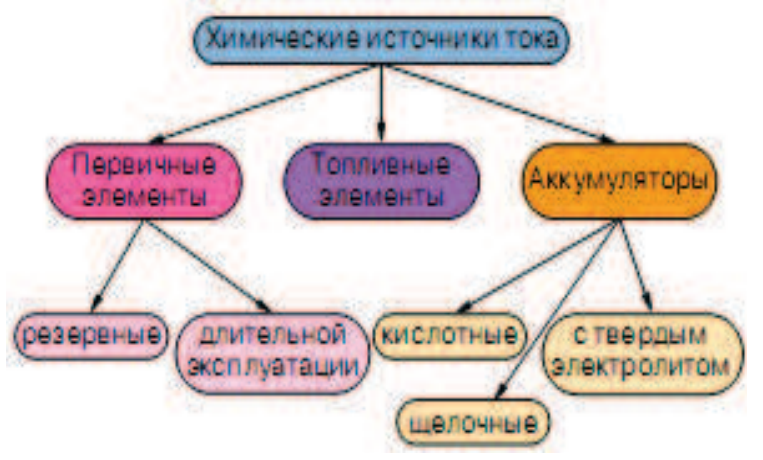

Рисунок 4 - Схема классификации ХИТ

Для выбора «идеальных» электрохимических систем с высокой способностью накопления используются следующие критерии выбора:

- химическая энергия связи компонентов в реакции, т.е. их химическое сродство должно быть как можно больше, чтобы получить высокий показатель напряжения в аккумуляторе.

- компоненты реакции должны иметь наименьшую атомную массу, в то время как накапливаемая энергия должна быть наибольшей.

В таблице 2 представлен набор химических элементов, которые могут это обеспечить. Верхний ряд - водород и легкие металлы, среди которых по всем параметрам выделяется литий.

На практике же не всегда удается справиться с комбинацией сильного окислителя и сильного восстановителя в одном источнике. 
Таблица 2

\begin{tabular}{|c|c|c|c|c|}
\hline \multicolumn{5}{|c|}{ Возможности аккумулирования комбинаций электродов, Вт·час/кг } \\
\hline \multirow[t]{2}{*}{+} & \multicolumn{4}{|c|}{-} \\
\hline & $\mathrm{H}_{2}$ & $\mathrm{Li}$ & $\mathrm{Na}$ & $\mathrm{Mg}$ \\
\hline $\mathrm{F}_{2}$ & $4100(3,06 \mathrm{~B})$ & $6270(6,07 \mathrm{~B})$ & $3588(5,62 \mathrm{~B})$ & $4690(5,45 \mathrm{~B})$ \\
\hline $\mathrm{Cl}_{2}$ & $1000(1,36 \mathrm{~B})$ & $2520(3,99 \mathrm{~B})$ & $1830(3,99 \mathrm{~B})$ & $1732(3,08 \mathrm{~B})$ \\
\hline $\mathrm{Br}_{2}$ & $354(1,07 \mathrm{~B})$ & $1116(3,62 \mathrm{~B})$ & $941(3,61 \mathrm{~B})$ & $755(2,59 \mathrm{~B})$ \\
\hline
\end{tabular}

Характеристики некоторых реально работающих систем представлены на рисунке 5 и в таблице 3.
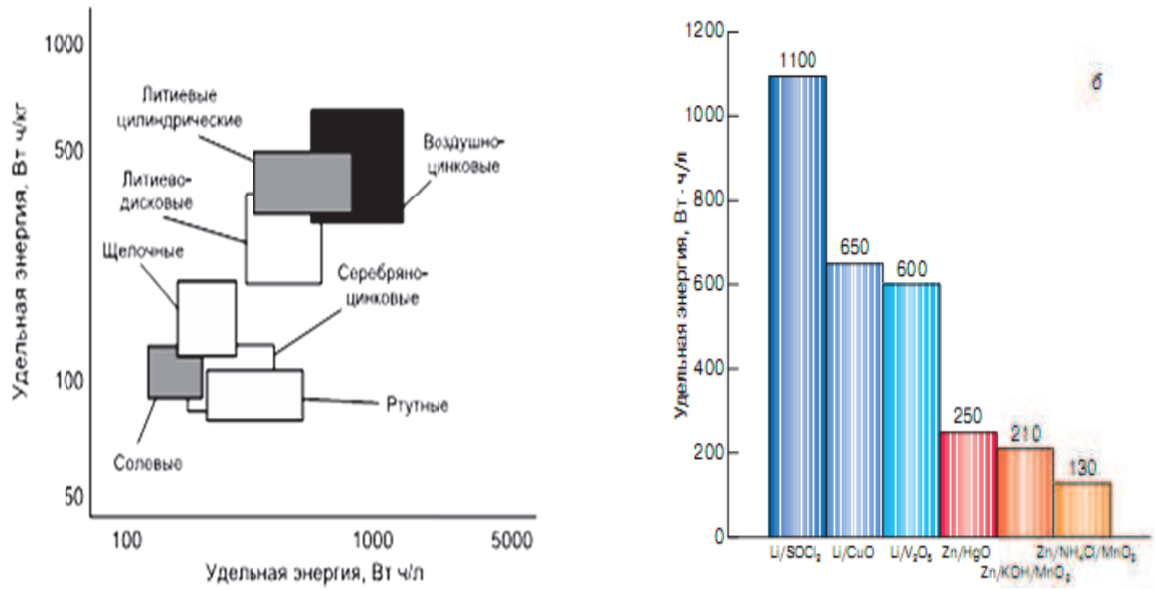

Рисунок 5 - Сравнение удельной энергии, достигнутой в наиболее распространенных первичных системах

Таблица 3 - Параметры первичных химических источников тока

\begin{tabular}{|c|c|c|c|c|c|c|}
\hline Система & $\begin{array}{l}\text { Напряжение, } \\
\text { В, } \\
\text { среднее/коне } \\
\text { чное }\end{array}$ & $\begin{array}{l}\text { Удельная } \\
\text { энергия*, Вхч/кг } \\
\text { / Вхч/л }\end{array}$ & $\begin{array}{l}\text { Удельная } \\
\text { мощность }\end{array}$ & $\begin{array}{l}\text { Рабочая } \\
\text { температур } \\
\mathrm{a},{ }^{\circ} \mathrm{C}\end{array}$ & $\begin{array}{l}\text { Рекомендуемая } \\
\text { температура } \\
\text { хране:ния, }{ }^{\circ} \mathrm{C}\end{array}$ & $\begin{array}{l}\text { Саморазряд при } \\
20{ }^{\circ} \mathrm{C}, \% \text { в год }\end{array}$ \\
\hline $\begin{array}{l}\mathrm{Zn} \mid \mathrm{ZnCl}{ }_{2} \\
\mathrm{NH}_{4} \mathrm{Cl} \mid \mathrm{MnO}_{2}\end{array}$ & $1,25-1,1 / 0,9$ & $65 / 100$ & Низкая & $-5-45$ & $0-20$ & 10 \\
\hline $\mathrm{Zn}\left|\mathrm{ZnCl}{ }_{2}\right| \mathrm{MnO}_{2}$ & $1,25-1,1 / 0,9$ & $85 / 165$ & $\begin{array}{l}\text { От низкой до } \\
\text { средней }\end{array}$ & $-10-50$ & $0-20$ & 7 \\
\hline $\mathrm{Zn}|\mathrm{KOH}| \mathrm{MnO}_{2}$ & $1,25-1,15 / 0,9$ & $125 / 330$ & Средняя & $-20-50$ & $-20-25$ & 4 \\
\hline $\mathrm{Zn}|\mathrm{KOH}| \mathrm{HgO}$ & $1,3-1,2 / 0,9$ & $105 / 325$ & Средняя & $0-55$ & $-20-25$ & 3 \\
\hline $\mathrm{Zn}|\mathrm{KOH}| \mathrm{Ag}_{2} \mathrm{O}$ & $1,6-1,5 / 1,0$ & $(120 / 500)^{* *}$ & Средняя & $0-55$ & $-20-25$ & 6 \\
\hline $\mathrm{Zn}|\mathrm{KOH}|$ воздух & $1,3-1,1 / 0,9$ & $(340 / 750)^{* *}$ & Низкая & $0-50$ & $-20-25$ & 2 \\
\hline $\begin{array}{l}\mathrm{Li}\left|\mathrm{LiClO}_{4}, Д О Л\right| \\
\mathrm{CuO}_{2}\end{array}$ & $1,5-1,4 / 0,9$ & $285-300 / 480-600$ & Низкая & $-20-60$ & $-20-40$ & $1-2$ \\
\hline 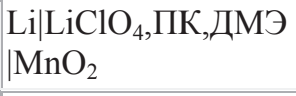 & $3,0-2,7 / 2,0$ & $230 / 550$ & Средняя & $-20-55$ & $-20-40$ & $1-2$ \\
\hline $\begin{array}{l}\mathrm{Li}|\mathrm{LiBF} 4, Б Л+\mathrm{T} Ф \Phi|( \\
\mathrm{CF}) \mathrm{n}\end{array}$ & $2,7-2,6 / 2,3$ & $220 / 410$ & $\begin{array}{l}\text { От низкой до } \\
\text { средней }\end{array}$ & $-20-50$ & $-20-40$ & $0,5-1$ \\
\hline $\mathrm{Li}|\mathrm{LiBr}, \mathrm{AH}| \mathrm{SO}_{2}$ & $2,9-2,7 / 2,0$ & $300 / 415$ & Высокая & $-55-70$ & $-20-40$ & 2 \\
\hline $\begin{array}{l}\mathrm{Li} \mid \mathrm{LiAlCl}_{4}, \mathrm{SOCl}_{2} \\
\mid \mathrm{SOCl}_{2}\end{array}$ & $3,5-3,2 / 3,0$ & $\begin{array}{l}320-650 / 700- \\
1000\end{array}$ & $\begin{array}{l}\text { От средней } \\
\text { до высокой }\end{array}$ & $-55-85$ & $-20-40$ & $1-6$ \\
\hline $\mathrm{Li}|\mathrm{LiCl}| \mathrm{I}_{2}, \Pi В \Pi$ & $2,8-2,6 / 2$ & $300 / 900$ & Очень низкая & $0-200$ & $0-4$ & 1 \\
\hline
\end{tabular}

*для цилиндрических элементов; ** - для дисковых элементов 
По стоимости первичные источники можно выстроить в следующий ряд: $\mathrm{Zn}\left|\mathrm{NH}_{4} \mathrm{Cl}\right| \mathrm{MnO}_{2}<\mathrm{Zn} /$ воздух $<\mathrm{Zn}|\mathrm{KOH}| \mathrm{MnO}_{2}<\mathrm{Li} / \mathrm{MnO}_{2}<\mathrm{Li} / \mathrm{SOCl}_{2}<\mathrm{Li} / \mathrm{SO}_{2}<\mathrm{Ag}_{2} \mathrm{O} / \mathrm{Zn}<$ $\mathrm{Li} / \mathrm{I}_{2}$. Однако по удельной стоимости (на единицу запасенной энергии) источники питания будут располагаться в другой ряд: $\mathrm{Zn} /$ воздух $<\mathrm{Zn}\left|\mathrm{NH}_{4} \mathrm{Cl}\right| \mathrm{MnO}_{2}<\mathrm{Li} / \mathrm{SOCl}_{2}<\mathrm{Zn}|\mathrm{KOH}| \mathrm{MnO}_{2}<$ $\mathrm{Li} / \mathrm{SO}_{2}<\mathrm{Li} / \mathrm{MnO}_{2}<\mathrm{Li} / \mathrm{I}_{2}<\mathrm{Ag}_{2} \mathrm{O} / \mathrm{Zn}$.

Приведенные ряды имеют оценочный характер. Реальная стоимость зависит от типоразмера и формы источника питания, объема производства и прочих факторов.

Чтобы отследить тенденцию развития ХИТ в последние годы, обратимся к данным одной из ведущих японских фирм - Matsushita (торговая марка Panasonic), занимающей по результатам 1998 года 29\% от производства ХИТ в Японии (Таблица 4 )

Таблица 4 - Объемы продаж ХИТ компанией Panasonic

\begin{tabular}{|c|c|c|c|c|c|c|c|c|}
\hline & $\begin{array}{c}\text { Первичные } \\
\text { элементы } \\
23 \% \\
\end{array}$ & \begin{tabular}{|c} 
Свинцовые \\
батареи \\
$7 \%$
\end{tabular} & $\begin{array}{c}\text { NiMH akкy- } \\
\text { мyляторы } \\
15 \%\end{array}$ & $\begin{array}{c}\text { N/Cd акку- } \\
\text { мyляторы } \\
8 \%\end{array}$ & $\begin{array}{c}\text { Литиевые } \\
\text { элементы } \\
12 \% \\
\end{array}$ & $\begin{array}{l}\text { L-ионные } \\
\text { аккумуляя- } \\
\text { торы } 17 \%\end{array}$ & $\begin{array}{l}\text { Li-nonимер- } \\
\text { њые аккумy. } \\
\text { ляторы } 3 \%\end{array}$ & $\begin{array}{c}\text { Прочия } \\
15 \%\end{array}$ \\
\hline & \multicolumn{8}{|c|}{ B MONHS $(\$ 1=115$ บen $)$} \\
\hline 1996 & 512 & 311 & 278 & 327 & 257 & 188 & 0 & 340 \\
\hline 1997 & 524 & 266 & 268 & 307 & 268 & 250 & 0 & 335 \\
\hline 1998 & 523 & 246 & 283 & 240 & 261 & 377 & 0 & 317 \\
\hline 1999 & 530 & 162 & 334 & 188 & 286 & 398 & 61 & 348 \\
\hline
\end{tabular}

Объем производства первичных марганцево-цинковых ХИТ остается на уровне, однако произошел существенный крен в сторону щелочных источников. Наблюдается устойчивая тенденция по выводу низкорентабельного производства солевых элементов на заводы вне Японии;

доля первичных литиевых ХИТ практически не меняется (1\% в год), однако происходит уменьшение продаж дисковых элементов (3...5\% в год);

продажи Ni-Cd батарей имеют устойчивую тенденцию к уменьшению (22\% в год);

продажи Ni-MH пока увеличиваются ( примерно12\% в год), но за счет сектора, ранее занимаемого Ni-Cd. При этом продажи призматических Ni-MH падают за счет интенсивного вытеснения их Li-ионными и Li-полимерными аккумуляторами;

Li-ионные аккумуляторы затормозили свой рост за счет передачи части рынка новой системе - Li-полимер, при этом увеличивается доля призматических аккумуляторов в основном из-за требований, выдвигаемых телефонией;

в целом сектор аккумуляторов имеет ощутимую тенденцию к росту продаж $(7-10 \%$ в год).

Для автономного обеспечения энергией все большую роль играют аккумулирующие системы, среди которых способ электрохимического запасения является непревзойденным по многим показателям, особенно по значению удельной емкости и энергии.

На рисунке 6 представлена сопоставительная диаграмма характеристик аккумуляторов, из которой также следует, что наиболее выдающимися значениями ее обладают литиевые системы.

Свинцовые аккумуляторы, хотя и имеют самое малое значение удельной энергии, еще много лет будут работать на рынке ввиду их высокой мощности.

Таким образом, литиевые источники тока характеризуются наибольшей теоретической удельной электрической энергией. Вторичные источники тока на основе лития обладают высоким разрядным напряжением и значительной емкостью.

Удельные характеристики литий-ионных аккумуляторов по крайней мере вдвое превышают аналогичные показатели никель-кадмиевых аккумуляторов и хорошо характеризуют себя при работе в средних режимах, что необходимо, например, при использовании данных аккумуляторов в сотовых телефонах и портативных компьютерах. Литий-ионные аккумуляторы имеют достаточно низкий саморазряд (2-5\% в месяц). 


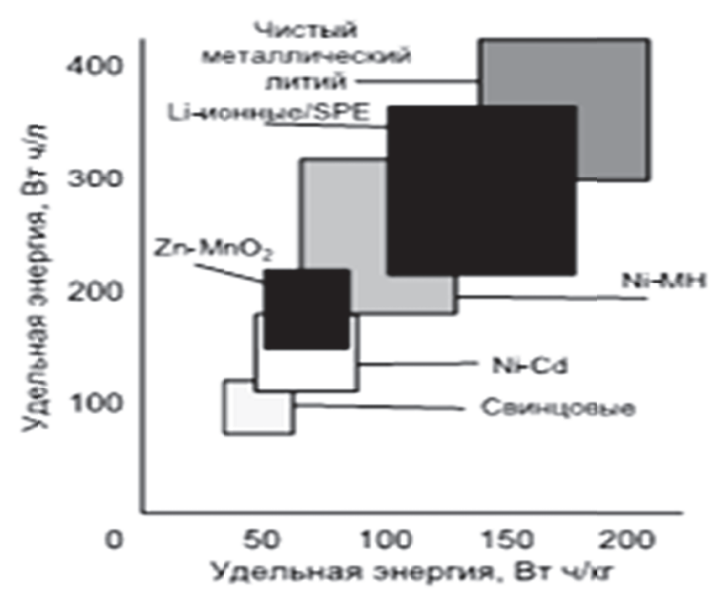

Рисунок 6 - Сравнение удельных энергий различных вторичных систем

Очень важной характеристикой аккумуляторов является ориентировочная относительная стоимость 1 Вт ' ч энергии, полученной от различных типов аккумуляторов одинаковой емкости.

Наиболее дешевы в использовании свинцово-кислотные аккумуляторы, которые и получили наибольшее распространение.

Таблица 5 - Сравнение никель-кадмиевых, металл-гидридных и литиевых систем

\begin{tabular}{|c|c|c|c|}
\hline & $\mathrm{Ni}-\mathrm{Cd}$ & Ni-MH & Lі-ион \\
\hline Стоимость одного А·ч & Низкая & Средняя & Высокая \\
\hline Экологичность & $\mathrm{Cd}$ токсичен & Не определена & Не определена \\
\hline Анод & $\mathrm{Cd}(\mathrm{OH})_{2}$ & AB 5 & Графит \\
\hline Катод & $\mathrm{Ni}(\mathrm{OH})_{2}$ & $\mathrm{Ni}(\mathrm{OH})_{2}$ & $\mathrm{LiCoO}_{2}$ \\
\hline Электролит & Щелочь & Щелочाь & Органический \\
\hline Номинальное напряжение, В & 1,2 & 1,2 & 3,7 \\
\hline Объемная энергия, Вт•ч/л & $120 \ldots 150$ & $250 \ldots 300$ & $280 \ldots 320$ \\
\hline Удельная энергия, Вт·ч/кг & $40 \ldots 55$ & $60 \ldots 80$ & $110 \ldots 130$ \\
\hline Ток разряда, макс, А & $10 \mathrm{C}$ & $4 \mathrm{C}$ & $2 \mathrm{C}$ \\
\hline Нижняя температура, ${ }^{\circ} \mathrm{C}$ & -40 & -20 & -20 \\
\hline Верхняя температура, ${ }^{\circ} \mathrm{C}$ & 70 & 50 & 60 \\
\hline Саморазряд, \% в месяц & $15-20$ & 30 & 10 \\
\hline Количество циклов & 1000 & 1000 & 1000 \\
\hline Чувствительность к перезаряду & Низкая & Средняя & Высокая \\
\hline Безопасность & Без замечаний & $\begin{array}{l}\text { Возможно } \\
\text { возгорание } \\
\text { проколе }\end{array}$ & $\begin{array}{l}\text { Требует } \\
\text { внутренних } \\
\text { электронных } \\
\text { устройств }\end{array}$ \\
\hline
\end{tabular}

Тенденции развития аккумулирующих систем хорошо видны по динамике их продаж (таблица 6):

Литий-ионные аккумуляторы являются наиболее дорогими из доступных сегодня на рынке. Совершенствование технологии производства и замена оксида кобальта на менее дорогой материал может привести к уменьшению их стоимость на 50\% в течение ближайших лет.

Наиболее перспективной из современных технологий считается доработка уже знакомых нам литиевых реакций и создание на их основе литий-твердополимерного элемента. В настоящее время большинство производителей аккумуляторов переключаются на эту технологию. 
Таблица 6 - Структура рынка по различным системам в 2000 и 2010 г.г.

\begin{tabular}{|c|r|r|}
\hline & 2000 & 2010 \\
\hline \hline Объем рынка в млрд. долл. США & 27 & 45 \\
\hline \hline Свинцово-кислотные аккумуляторы & $80 \%$ & $53 \%$ \\
\hline \hline Li-ионные аккумуляторы & $8 \%$ & $11 \%$ \\
\hline \hline NiMn аккумуляторы & $4 \%$ & $29 \%$ \\
\hline \hline NiCd аккумуляторы & $7 \%$ & $5 \%$ \\
\hline Другие аккумуляторы & $1 \%$ & $1 \%$ \\
\hline \hline
\end{tabular}

Тогда как в традиционных литий-ионных элементах используется жидкий электролит, в твердополимерных элементах электролит запечатан в полимерную пластиковую прокладку, находящуюся между электродами аккумулятора.

В качестве электролита такие элементы используют полимерные композиционные материалы с содержанием солей лития. Так как это вовсе не жидкость, а твердый материал, новые батарейки не требуют громоздких цилиндрических корпусов, как у традиционных элементов. Вместо этого элементы производятся в форме плоских многогранников, которые легче умещаются в батарейные отсеки ноутбуков.

Одним из основных недостатков литиевых аккумуляторов является их невысокая мощность, что не позволяет использовать их для электромобиля. Для решения этой проблемы сейчас широко разрабатывается новый вариант литий-железофосфатных аккумуляторов. В отличие от других литиевых элементов, где стремятся увеличить плотность энергии, в этих элементах реализовано компромиссное решение для увеличения мощности.

Литий-железодисульфидные элементы легко выдерживают большие нагрузки. Они могут питать мощные устройства дольше щелочных элементов такого же размера.

В целом, достигнутый уровень ЛИА характеризуется следующими показателями:

Разрядное напряжение

Ресурс

Удельная энергия

Саморазряд

Диапазон температур

Максимальный ток разряда

Нижний порог напряжения
$3.5-3.7 \mathrm{~B}$

$500-1000$ циклов

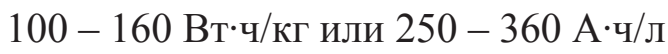

$6-10 \%$ в месяц

$-20 \div+600 \mathrm{C}$

$2 \mathrm{C}$

2.5 или $2 \mathrm{~B}$

Конструктивно Li-ion аккумуляторы, как и щелочные ( $\mathrm{Ni}-\mathrm{Cd}, \mathrm{Ni}-\mathrm{MH})$, производятся в цилиндрическом и призматическом вариантах. В цилиндрических аккумуляторах свернутый в виде рулона пакет электродов и сепаратора помешен в стальной или алюминиевый корпус, с которым соединен отрицательный электрод. Положительный полюс аккумулятора выведен через изолятор на крышку (рисунок 7). Призматические аккумуляторы производятся складыванием прямоугольных пластин друг на друга. Призматические аккумуляторы обеспечивают более плотную упаковку в аккумуляторной батарее, но труднее, чем в цилиндрических, поддерживать сжимающие усилия на электроды. В некоторых призматических аккумуляторах применяется рулонная сборка пакета электродов, который скручивается в эллиптическую спираль. Это позволяет объединить достоинства двух описанных выше модификаций конструкции. 


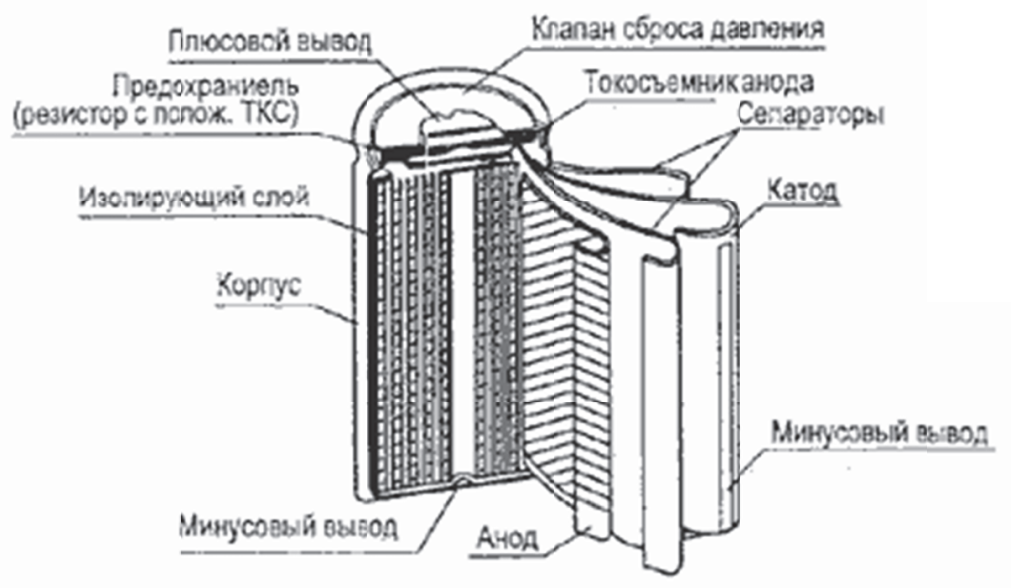

Рисунок 7 - Устройство литий-ионного (Li-ion) аккумулятора

Для повышения безопасности эксплуатации Li-ion аккумуляторов в составе батареи обязательно применяется также и внешняя электронная защита, цель которой не допустить возможность перезаряда и переразряда каждого аккумулятора, короткого замыкания и чрезмерного разогрева. Конструкция Li-ion и других литиевых аккумуляторов, как и конструкция всех первичных источников тока ("батареек") с литиевым анодом, отличается абсолютной герметичностью. Требование абсолютной герметичности определяется как недопустимостью вытекания жидкого электролита (отрицательно действующего на аппаратуру), так и недопустимостью попадания в аккумулятор кислорода и паров воды из окружающей среды. Кислород и пары воды реагируют с материалами электродов и электролита и полностью выводят аккумулятор из строя. Источники тока с более высокими энергетическими характеристиками и расширенным диапазоном эксплуатационных возможностей были разработаны при отказе от водных электролитов. Самые большие успехи были достигнуты при разработке первичных литиевых элементов с органическим и твердым электролитом. Первые работы по применению лития в качестве анодного материала в источниках тока появились в начале XX века, но реальное развитие они получили в 60-ых годах. Изучались источники тока с твердофазными $\left(\mathrm{MnO}_{2}, \mathrm{CuO}, \mathrm{I}_{2}, \mathrm{CFx}, \mathrm{FeS}_{2}\right.$ и другие) и жидкофазными катодными материалами $\left(\mathrm{SO}_{2}\right.$ и $\left.\mathrm{SOCl}_{2}\right)$. Основные характеристики литиевых элементов более всего распространенных систем показаны в таблице 7, ниже описаны их особенности и показаны рабочие характеристики.

Таблица 7 - Литиевые элементы различных электрохимических систем

\begin{tabular}{|c|c|c|c|c|c|c|}
\hline Характеристики & $\mathrm{Li} / \mathrm{MnO}_{2}$ & $\mathrm{Li} / \mathrm{SO}_{2}$ & $\mathrm{Li} / \mathrm{SOCl}_{2}$ & $\mathrm{Li} / \mathrm{CFx}$ & $\mathrm{Li} / \mathrm{CuO}$ & $\mathrm{Li} / \mathrm{I}_{2}$ \\
\hline НРЦ & 3,5 & 3,0 & 3,67 & 3,3 & 1,6 & 2,8 \\
\hline Рабочее напряжение, В & 3,0 & $2,6-2,9$ & $3,3-3,5$ & - & $1,2-1,5$ & \\
\hline Конечное напряжение, В & 2,0 & 2,2 & 2,2 & 2,0 & $0,9-1,0$ & 2,2 \\
\hline $\begin{array}{lr}\text { Удельная } & \text { энергия: } \\
\text { Весовая, } & \text { Втч/кг }\end{array}$ & до 250 & $300-340$ & до 600 & 250 & 300 & - \\
\hline Объемная, Втч/л & 500 & $500-560$ & до 1100 & 600 & 600 & $\begin{array}{l}\text { до } \\
1000\end{array}$ \\
\hline $\begin{array}{ll}\text { Диапазон } & \text { рабочих } \\
\text { температур, }{ }^{\circ} \mathrm{C} & \end{array}$ & $20-+55$ & $60-+70$ & $\begin{array}{l}50-+70 \\
(\text { до } 130)\end{array}$ & $\begin{array}{l}20- \\
+60\end{array}$ & $\begin{array}{l}10- \\
+70\end{array}$ & $\begin{array}{l}10- \\
+60 \\
\end{array}$ \\
\hline Саморазряд, \% в год & $2-2,5$ & $1-2$ & $1,5-2$ & $1-2$ & $1-2$ & 1 \\
\hline
\end{tabular}

Литиевые батарейки в настоящее время в ряде областей техники успешно конкурируют с более дешевыми элементами с водным электролитом. Их применяют в часах, фотокамерах, калькуляторах, для защиты памяти интегральных схем, в измерительных приборах и 
медицинском оборудовании, там, где требуется высокая сохранность и постоянство рабочего напряжения в течение многих лет эксплуатации.

Существуют и мощные источники тока, способные к отдаче импульсов большой энергии даже после 10-12 лет хранения.

Глобальный рынок аккумуляторов оценивается в \$50 млрд. В 2010 г. рынок литиевых аккумуляторов оценивался в $\$ 878$ млн., но согласно прогнозам Pike Research в 2015 г. этот показатель будет уже равен \$5 млрд. Согласно прогнозам американской FMC Corp. (поставляющей литий для автопрома), на протяжении следующего десятилетия спрос на литиевые аккумуляторы будет расти на 9\% в год. Значительные запасы лития сосредоточены в РФ (Кольский полуостров, Тува и Забайкалье), а также в Казахстане и Узбекистане.

На рисунке 8 представлены лидеры поставщиков литиевых аккумуляторов. Самая большая часть рынка принадлежит Sanyo Electric - 20\%, далее Samsung SDI (Южная Корея) - 18\%, LG Chem (Южная Корея) - 15\%, Sony - 12\%, Panasonic - 7\%, BYD (Китай) - 6\%, и $12 \%$ принадлежит остальным компаниям.

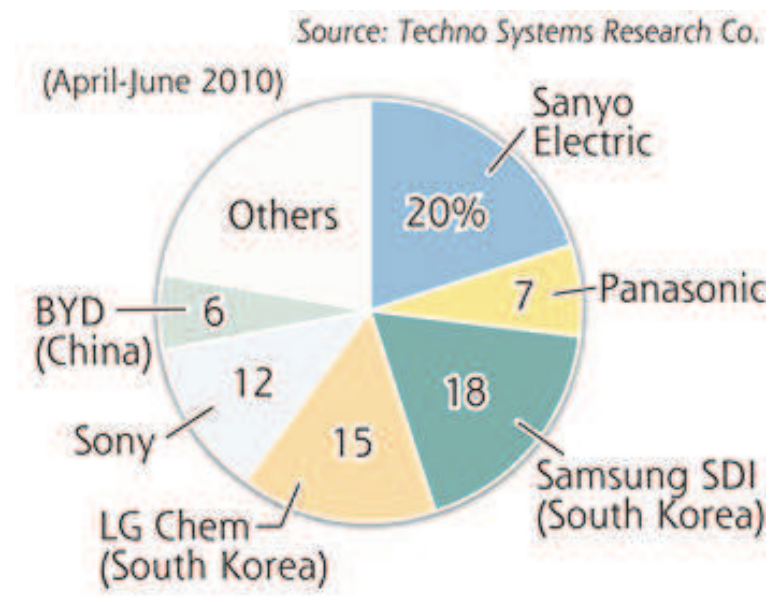

Рисунок 8 - Ведущие поставщики литиевых аккумуляторов

На сегодняшний день ведутся споры, хватит ли лития для удовлетворения спроса в будущем для производства аккумуляторов особенно для гибридных и электромобилей.

Аналитическое агентство JP Morgan представило свой прогноз производства электромобилей. К примеру, к 2015 г. уровень производства будет равен 590000 электромобилей, в 2017 г. производственный показатель будет равен 1040000 электромобилей. В 2020 году прогноз производства составляет 12930000 автомобилей. По сообщению Председателя Правления корпорации Nissan, электромобили будут составлять $10 \%$ мирового спроса в 2020 г. при цене за баррель нефти в $70 \$$.

По состоянию на 2011 г. литиевые аккумуляторы добавляют к стоимости автомобиля от $\$ 8000$ до $\$ 18000$ (в зависимости от размеров) и являются одним из дорогих компонентов в сборке автомобиля. Исследовательское агентство Fuji Keizai Group прогнозирует, что средняя цена литиевых аккумуляторов, которые будут использованы в гибридных и электромобилях скорей всего упадет на 50\% в 2014 г. благодаря техническому совершенству и массовому производству и составит примерно от $\$ 4000$ до $\$ 9000$.

Литий-ионные аккумуляторы широко применяется как в общегражданской технике, так и в изделиях специального назначения. Наибольшее количество аккумуляторов используется в сотовых телефонах. Так, по данным на 2000 г. 67 \% всех литий-ионных и литийполимерных аккумуляторов было предназначено для сотовых телефонов, 24 \% - для портативных персональных компьютеров (ноутбуков) и 9 \% приходилось на все остальные области применения. Годовое производство литий-ионных аккумуляторов для сотовых телефонов в 2000-2005 гг. приблизительно будет равно 250- 400 млн штук. Хотя для питания сотовых телефонов наряду с литий-ионными широко используются также никель- 
металлогидридные аккумуляторы, доля первых значительно возрастает. Уже сейчас около 98 \% всех мобильных телефонов, производимых в Японии, оснащены литий-ионными аккумуляторами. И эта тенденция на ближайшее время неодолима.

\title{
ЭНЕРГЕТИКАДАҒЫ ЭЛЕКТРОХИМИЯЛЫК ЭНЕРГИЯ ӨЗГЕРТУШЕЛЕРДІҢ ОРНЫ МЕН РӨЛІ
}

\author{
А.П.Курбатов
}

Энергияны жалпы өндіру процесіндегі химиялық реакцияның энергиясын түрлендірудің электрохимиялық әдісінің орны қараластырылған. Оны жүзеге асырудың эффективті жолдары мен үрдістері көрсетілген. Энергияны алуға, жинақтауға және сақтауға арналған электрохимиялық жүйелер нұсқалары қарастырылған.

\section{PLACE AND ROLE OF ELECTROCHEMICAL CONVERTERS IN THE ENERGETICS}

\section{A.P. Kurbatov}

The position of the electrochemical method of energy conversion of a chemical reaction in the overall energy production was considered. The effective ways and tendencies of its implementation were shown. The variants of electrochemical systems for the production, accumulation and storage of energy was also considered.

УДК 634.0.861.16

\section{ИЗУЧЕНИЕ ФИЗИКО-ХИМИЧЕСКИХ ХАРАКТЕРИСТИК ШУНГИТОВЫХ ПОРОД}

\author{
М.К.Казанкапова, С.В.Нечипуренко, С.А.Ефремов, М.К.Наурызбаев
}

Казахский национальный университет имени аль-Фараби, г.Алматы

Методами элементного анализа, ИК-спектроскопии и электронной микроскопии изучены физикохимические характеристики цунгитовых пород Казахстана (месторождение «Бакырчик») и России (месторождение «Зажегино»). Определено содержание углерода в шунгитовой руде месторождения «Зажегино», составляет 28,0-31,0 \%, в руде месторождения «Бакырчик» - 15,0-19,0 \%, шунгитовом

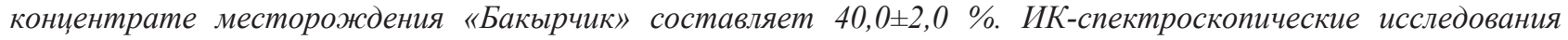
показали, что в концентрате помимо полициклических углеводородов, содержаших метиленовые группы, появляются карбоксильные группы. Исследования электронной микроскопии показали, что в результате обогащения шунгитовых пород по углероду можно получить более развитую поверхностную структуру и nористость.

\section{Введение}

Экологическая напряженность, возникшая в последние десятилетия, может быть снята посредством последовательного практического решения экологических проблем. В связи с этим ключевое значение приобретает переосмысление всех сфер человеческой деятельности и, в первую очередь, науки, как решающего фактора социально-экономического развития страны.

В последнее время все более усугубляется проблема загрязнения природных объектов отходами техногенного происхождения. Различные виды отходов промышленных предприятий отравляют воздушный бассейн, водную акваторию и почву, оказывая пагубное воздействие на обитающие в них живые организмы. Серьезной экологической проблемой, требующей безотлагательного решения, является загрязнение водных ресурсов и почвы нефтью и нефтепродуктами, тяжелыми металлами, пестицидами и др. веществами.

Распространенными методами очистки воды, воздуха и почв являются адсорбционные методы. Однако большинство известных сорбентов имеют общие недостатки (высокая стоимость, низкая сорбционная емкость и др.). Производство сорбентов традиционным 